NASA/TM-2003-212808

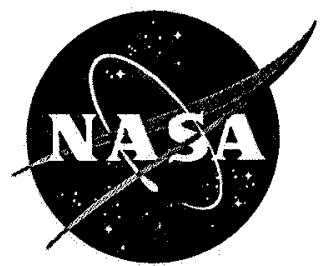

Perspective Imagery in Synthetic Scenes used to Control and Guide Aircraft during Landing and Taxi: Some Issues and Concerns

Walter W. Johnson and Mary K. Kaiser

Ames Research Center, Moffett Field, California

December 2003 
Since its founding, NASA has been dedicated to the advancement of aeronautics and space science. The NASA Scientific and Technical Information (STI) Program Office plays a key part in helping NASA maintain this important role.

The NASA STI Program Office is operated by Langley Research Center, the lead center for NASA's scientific and technical information. The NASA STI Program Office provides access to the NASA STI Database, the largest collection of aeronautical and space science STI in the world. The Program Office is also NASA's institutional mechanism for disseminating the results of its research and development activities. These results are published by NASA in the NASA STI Report Series, which includes the following report types:

- TECHNICAL PUBLICATION. Reports of completed research or a major significant phase of research that present the results of NASA programs and include extensive data or theoretical analysis. Includes compilations of significant scientific and technical data and information deemed to be of continuing reference value. NASA counterpart of peer-reviewed formal professional papers, but having less stringent limitations on manuscript length and extent of graphic presentations.

- TECHNICAL MEMORANDUM. Scientific and technical findings that are preliminary or of specialized interest, e.g., quick release reports, working papers, and bibliographies that contain minimal annotation. Does not contain extensive analysis.

- CONTRACTOR REPORT. Scientific and technical findings by NASA-sponsored contractors and grantees.
- CONFERENCE PUBLICATION. Collected papers from scientific and technical conferences, symposia, seminars, or other meetings sponsored or co-sponsored by NASA.

- SPECIAL PUBLICATION. Scientific, technical, or historical information from NASA programs, projects, and missions, often concerned with subjects having substantial public interest.

- TECHNICAL TRANSLATION. English-language translations of foreign scientific and technical material pertinent to NASA's mission.

Specialized services that complement the STI Program Office's diverse offerings include creating custom thesauri, building customized databases, organizing and publishing research results ... even providing videos.

For more information about the NASA STI Program Office, see the following:

- Access the NASA STI Program Home Page at $h$ ttp://www.sti.nasa.gov

- E-mail your question via the Internet to help@sti.nasa.gov

- Fax your question to the NASA STI Help Desk at (301) 621-0134

- Telephone the NASA STI Help Desk at (301) 621-0390

- Write to:

NASA STI Help Desk

NASA Center for AeroSpace Information

7121 Standard Drive Hanover, MD 21076-1320 
NASA/TM-2003-212808

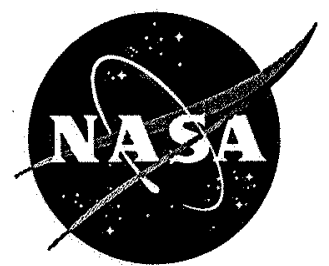

\section{Perspective Imagery in Synthetic Scenes used to Control and Guide Aircraft during Landing and Taxi: Some Issues and Concerns}

Walter W. Johnson and Mary K. Kaiser.

Ames Research Center, Moffett Field, California

National Aeronautics and

Space Administration

Ames Research Center

Moffett Field, California 94035

December 2003 
Available from:

NASA Center for AeroSpace Information 7121 Standard Drive

Hanover, MD 21076-1320

301-621-0390
National Technical Information Service 5285 Port Royal Road Springfield, VA 22161

703-605-6000

This report is also available in electronic form at http://human-factors.arc.nasa.gov/ihh/cdti/index.html 


\section{Summary}

Perspective synthetic displays that supplement, or supplant, the optical windows traditionally used for guidance and control of aircraft are accompanied by potentially significant human factors problems related to the optical geometric conformality of the display. Such geometric conformality is broken when optical features are not in the location they would be if directly viewed through a window. This often occurs when the scene is relayed or generated from a location different from the pilot's eyepoint. However, assuming no large visual/vestibular effects, a pilot can often learn to use such a display very effectively. Important problems may arise, however, when display accuracy or consistency is compromised, and this can usually be related to geometrical discrepancies between how the synthetic visual scene behaves and how the visual scene through a window behaves. In addition to these issues, this paper examines the potentially critical problem of the disorientation that can arise when both a synthetic display and a real window are present in a flight deck, and no consistent visual interpretation is available.

\section{Introduction}

Synthetic perspective displays stand in contrast to most aircraft flight deck displays which provide specific vehicle-state variables and guidance cues, and which supply the pilot with general situational/spatial awareness. Examples of such instruments are the traditional attitude direction indicator, turn coordinator, airspeed indicator, heading indicator, and vertical speed indicator, with these being displayed either on panelmounted displays (PMDs), or within a head-up display (HUD). These instruments have been developed primarily by controls engineers who typically tailor these control-display concepts in a series of simulations using measured performance and subjective handling qualities ratings (ref. 1). Although the aviation community is very comfortable with this type of instrument suite (some of which are based on quite advanced concepts (refs. 2 and 3)), a growing body of literature generated by human factors researchers suggests that the naturally integrated and nonsymbolic nature of the perspective scene as sampled through a flight deck window is often, but not always, a superior source of information, providing the pilot with information in a very familiar format for guidance and control, and giving good spatial and temporal preview of the intended path.(refs. 4 and 5).

Further, conventional avionic displays such as described above are of really very limited utility during aircraft surface operations, where the perspective scene sampled through a flight deck window is the primary source of information for ground control and guidance. That is, other than paper maps and perhaps a ground speed display, there are almost no instruments or displays on the flight deck useful for ground guidance, control, and object detection and avoidance. Nor has anyone suggested a display that permits a pilot to directly guide and control surface movement as well as he can do this with flight deck windows on a clear day.

However, as a result of the acknowledged value of naturalistic perspective scenes for guidance and control, and as a result of the growing body of literature on the advantage of integrated displays, there has been an effort to create flight deck displays that have an integrated perspective format (refs. 6 and 7). These displays, which attempt to partially replace or supplement the perspective scene available through the window of the aircraft, can be termed virtual windows since, like windows, they approximate the boundaries or edges of an aperture, and thus approximate a window into a virtual space (i.e. a simulated projection). Additional guidance for this effort has also come from the work on visual cues used for vehicle control(refs. 8, 9, 10,11, 12, 13, 14), and simulation cueing requirements (refs. 15 and 16).

Unfortunately, while there has been a great deal of research on the desirable properties of such integrated 3-D displays, there has been little examination of the human factors problems that may arise when one attempts to incorporate such displays into a real flight deck. This paper is an examination of some selected issues in this area that the authors have encountered in the course of 
their work on flight deck displays. The organization of this paper will be to first briefly describe some of the salient properties of real flight deck windows, and then to very briefly describe some of the technologies that are available at present to support the implementation of virtual windows. Next there will be a discussion of the human factors concerns that stem from differences between displays generated using these technologies and the visual display available with a real window.

\section{Properties of Windows}

To the extent that a rendered perspective scene is an approximation of a true window, we may ask: "what are the characteristics of the true window that may or may not be present in a virtual window?" The following is a short list of relevant window properties. Many other, perhaps equally important, properties could be described. However, these factors are especially relevant for the issues raised in the remainder of the paper.

First, there is the correspondence between the visual content of a true window and the visual content of a rendered space. Ignoring considerations of glare and a dirty window, a true window faithfully shows what is on the other side of it, including other aircraft, atmospheric conditions (weather), and the general airport layout. Furthermore, in low-visibility conditions it does not show much of the world. This is in contrast to a virtual window which, depending upon the technology behind it, may show only part of what is in the world behind it, and may also introduce elements that are not in the world. For example, a perspective display that is solely derived from a computer-generated imagery (CGI) database will not be subject to the visibility limitations of weather, and may depict useful signage not actually present in the real world, but will also not capture elements in the world that are not a part of this database (e.g. an approaching vehicle).

Second, the perspective scene sampled through a window always obeys optical laws relating the location of the objects in the world, to the location of the window on the aircraft, and to the location of the observers on the flight deck. For example, the field of view (FOV) and field of regard (FOR), made available by the window, and the optical location of a particular object within the window, are always specific to the location of the observer's eye(s) (i.e. are different for every potential observer location on the flight deck). For the case of multiple flight deck windows this means that there is a unique set of correct views through these windows for every location on the flight deck. This is in contrast to synthetic perspective displays which may not all be drawn from the single perspective point of view of the pilot.

Third, the optical transformations or changes within true windows are always specifically linked to the vestibular stimulation of the observer. Thus movements of the scene within the windows always specify the movement of the pilot's head within the flight deck, or of the flight deck itself. This is in contrast to synthetic perspective displays that may not change when the pilot moves his head, or which may pan and zoom without any movement of the aircraft or the pilot.

Fourth, moving the eyes relative to a window produces several salient optical changes. One change is a redefinition of the viewing volume (the portions of the outside world that can be seen). When you move closer to the window more of the outside world is viśible; when you move left, right, up or down new areas of the outside world are exposed to view and some of the old areas are occluded by the window boundary (see Figure 1). This reflects changes in the size of the field of view (FOV), and in the areas of the field of regard (FOR) which fill the FOV. For example, Figure 1 also shows that when you move closer, the FOV spanned by the window expands and is filled in by a larger portion of the FOR. On the other hand, when you move up, down, left, or right with respect to the window the viewed portion of the FOR may change substantially while the FOV may not change by a great amount.

Fifth, windows provide the appropriate stimulation for binocular vision, and thus for stereo vision and 
binocular vergence. Furthermore, since an observer's (or pilot's) eyes are laterally separated, the viewing volumes for the two eyes do not exactly overlap (binocular disparity), and the effective FOR is increased. Finally, since windows provide a true view in depth, they provide the appropriate stimulus for the ocular accommodation response.

Finally, it is very important to note that there is no temporal lag induced by transmission of light through a window. All changes or transformations of optical patterns occur instantaneously, or in "real time". This is in contrast to synthetic displays which always possess some degree of lag.

\section{Display Technologies}

We now need to briefly consider the nature of specific display technologies, since these will define both the capabilities and the limitations with regard to replicating the perspective scenes sampled through a true window. In doing this, we will ignore specific implementations and focus as generically as possible. Five such generic technologies have been identified below.

\section{Information Format}

First, there is the question of the format of the information that can be used. The two main types are viewpoint-based and coordinate-based. Viewpoint-based information is fundamentally 2$D$, and comes primarily from cameras (electrooptical, infra-red, etc.) in the form of an image. This type of format does not directly contain information about the 3-D spatial structure or location of the any of the imaged objects, but instead represents image characteristics (hue, saturation, brightness) in an image-coordinate space. Viewpoint-based systems typically can only generate imagery that is appropriate for a viewpoint (eye location) that is coincident with the location of the sensor (e.g. camera or FLIR), although image-warping techniques have been proposed that, within limits, can modify the image so it approximates the view from another (usually nearby) viewpoint (ref. 17).

Coordinate-based information, on the other hand, is fundamentally $3-\mathrm{D}$, and may be obtained from a database describing the layout of objects and
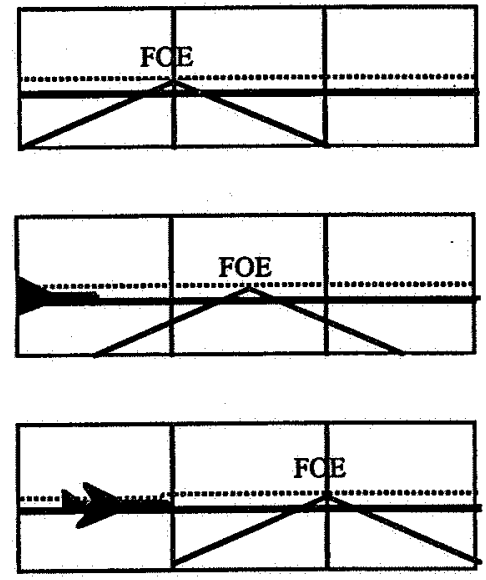

Viewpoint $2 \mathrm{ft}$ from Window

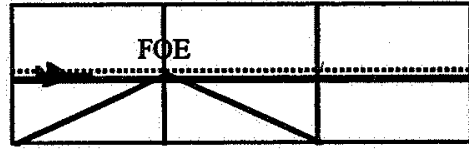

Captain's View

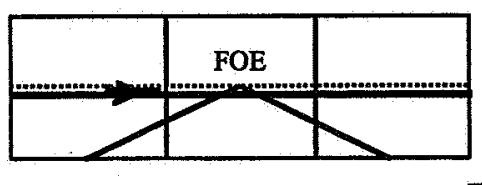

Center View

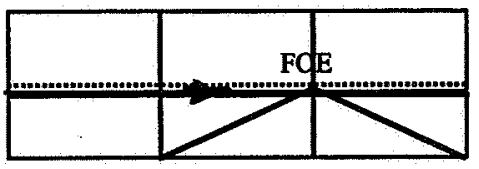

Viewpoint $1 \mathrm{ft}$ from Window

Figure 1. View out of three contiguous $2 \mathrm{ft} \times 2 \mathrm{ft}$. windows. The scene contains a taxiway intersection $367 \mathrm{ft}$. from the observer, and a $200 \mathrm{ft}$. aircraft on the crossing taxiway also $367 \mathrm{ft}$. from the intersection. The depicted incockpit viewing locations are $1 \mathrm{ft}$. and $2 \mathrm{ft}$. from the windows; and the Captain's location ( $1 \mathrm{ft}$. left of center), the First Officer's location ( $1 \mathrm{ft}$ right of center), and a center point equidistant between the Captain and the First Officer. 
surfaces (such as CGI database) or it may be obtained from sensor systems that can determine the range, elevation, and azimuth of surfaces that lie within the line of sight (such as RADAR, or some types of artificial vision systems that process the optical 2-D imagery). When coordinate-based systems are used, they can generate imagery that is appropriate for a variety of eye locations, since they store the information in a viewpoint independent manner. However, when the coordinate information comes from a sensor, and not a CGI database, there is no coordinate information for objects and surfaces that are not within the line of sight. Thus the ability to transform viewpoints is still limited.

Finally, mixed format systems have also been proposed. These systems attempt to capitalize on the relative strengths of the two technologies, fusing the information provided by optical and infrared cameras, CGI databases, and RADAR to produce an enhanced image. However, such systems still are very much in the research and development stage.

\section{HMD. vs. PMD}

Second, there are two main types of physical displays: helmet-mounted displays (HMDs) and panel-mounted displays (PMDs). A PMD is any display that is located in a fixed location within the flight deck. An HMD is any display that is worn at a fixed location relative to the eye, and may be totally or partially immersive. The display of a totally immersive HMD will cover the observer's entire effective FOV. Partially immersive HMDs have been designed to allow pilots to see the other displays and controls within the flight deck. These partially immersive displays are either see-through (see following description of display transparency) or only cover part of the observer's effective FOV (e.g. may only cover one eye, or only cover the upper part of the FOV, leaving the observer free to look underneath the display and see the control panel).

\section{Headtracking}

Third, displays can be head-tracked or not headtracked. An HMD usually requires some form of head-tracking so that the display is always optically correct for the head location and orientation. Some HMDs are not of this type, displaying text or other symbolic information, but these are not of interest in the present context. While PMDs have typically not been coupled with a head-tracker, this can be done in order to produce optical transformations that mimic those occurring in a real window (ref. 18).

\section{Transparency}

Fourth, displays can be either opaque or "seethrough". Opaque PMDs and HMDs are the more common displays. An example of a see-through PMD is a HUD. Such see-through HMDs (displayed on a glass monocle) have been used to present Apache helicopter pilots with both symbolic and sensor-derived perspective HUD displays useful for guidance, control, and for aiming weapons. Surface taxi applications are being presently explored that would use seethrough HUDs with scene-linked perspective symbology (ref. 19).

\section{Binocular vs. Biocular}

Fifth, displays can be either binocular (presenting different images to the two eyes) or biocular. Both binocular and biocular imagery can be presented in two ways. Binocular imagery can either be sensitive or insensitive to head orientation. When the display is insensitive to head orientation, the standard method of generating stereo displays presents images to each eye that reflect the expected lateral displacement of the eyes along the purely horizontal axis. That is, this display assumes that the head is being held in a level position (i.e. not tilted to the left or right). The advantage of this type of display is that it does not require head-tracking. However, if the observer tilts his or her head from side to side, then this changes the orientation of the axis along which disparity is defined. In addition, the display will be incorrect if the observer moves his or her head out of the correct location, or "eyebox", designated for the display. Therefore, only a system that calculates or obtains images that reflect head location and head roll will accurately capture these aspects of stereo vision. 
Biocular displays also come in two types. There are displays that show an image upon a picture plane, with the two eyes sampling this same image from slightly different perspectives. This is the normal case of picture viewing, and is one of the things that allows us to know that we are viewing a picture and not a real scene. Next there are displays that show the same image to both eyes, thus specifying that the image is somewhere behind the true picture plane. This can be accomplished with two methods. One method uses a head-mounted display (HMD) and presents the same image to the two eyes, with the image at optical infinity when no convergence is present. The other method uses a panel-mounted collimated display, with the image at optical infinity when the display is fully collimated.

\section{Human Factors Criteria}

The description of true windows can then guide our examination of displays as virtual windows. While limitations in available technology may make it impossible to replicate fully the properties of a true window, they do not preclude the generation of a virtual window that is useful and safely preserves many important perceptual properties of a window. But a successful implementation will require a methodical evaluation of how well the virtual window preserves these properties. This evaluation, in turn, should characterize virtual window adequacy with respect to a display's functional utility, and any physiological side effects produced by the use of the display. A display's functional utility reflects how well the pilot can use the optical information provided by the window to control and guide the aircraft, and to perform the required monitoring functions (e.g., target detection and weather monitoring). This is impacted both by the quality of the information contained in the display, and its compellingness or salience. Information quality reflects how accurate and complete the needed information is. Compellingness, or salience, reflects how likely a person is to pick up and use the information. A highly compelling display attribute can be a two-edged sword, however, depending upon the accuracy of the display attribute.
Simulation and telerobotic applications have also demonstrated the importance of the physiological side effects produced when synthetic perspective displays are used. These side effects all generally fall under the category of simulator sickness (e.g. nausea, headaches, and disorientation) which can accompany displays where there is cue conflict. Simulator sickness is most often seen in conflicts between visual and vestibular information (e.g. a simulator presents a visual display which specifies self-motion, but accompanies this with either no platform motion, or incorrect platform motion).

Finally, in order to guide this evaluation we need some principled method by which to organize our comparison of the physical fidelity of the virtual window with respect to a real window. Three attributes may be used to form the primary bases for evaluating this fidelity: geometric conformality, dynamic conformality, and image quality. This paper, however, is mainly concerned with issues of display conformality and will therefore examine only issues relevant to the first. two issues.

\section{Geometric Conformality}

Perfect geometric conformality is achieved when the locations of the imaged objects within the virtual space register exactly with the optical locations of the real objects as directly viewed by the observer. There are dangers to violating geometric conformality, but there may often be compelling reasons to do so. For example, there may be a requirement for a larger effective FOV while keeping the cost and weight of the display to a minimum hence necessitating minification. In addition, the desire for other instrumentation may also lead to limitations on the amount and location of flight deck territory given to the perspective display. This directly clashes with the needs of pilots who, during surface operations, are monitoring a very wide FOV for approaching ground traffic. Geometric conformality violations such as a minified display, which compresses the FOV (and thereby change the appropriate eyebox location), or a slewable display which extends the effective FOR to the left and right (and thereby simulates head movements without corresponding 
vestibular stimulation), appear very attractive options under such circumstances.

There may also be a desire to use cameras to supply the imagery since this eliminates, or mitigates, the need for: 1) an on-board CGI system for high-fidelity graphical rendering; 2) sensor technologies which automatically detect, identify, and/or localize transient objects or situations. (e.g. aircraft, ground vehicles, and weather conditions); and 3) complex and frequently updated airport CGI databases. These frequent updates are needed since the available runways and taxiways are constantly changing at airports due to construction and maintenance. (For example, on a site visit to Atlanta's Hartsfield International Airport the first author was told that significant changes can occur on a daily basis. Pilots are alerted to these changes both by published Airmen Advisories and signage on the airport surface.) However, as mentioned earlier, the camera supplies imagery that is appropriate for an eyepoint at the location of the camera, not the eyepoint of the pilot, and thus significant distortions in geometric conformality may ensue:

Most of the ways in which violations of geometric conformality in perspective displays affect perception and performance have not been studied. This is especially true for aerospace applications of perspective displays, since the main impetus in the most studied application area, flight simulation, has been to provide this conformality and not study its absence. However, it may not be possible to avoid significant compromises in geometric conformality when placing perspective displays within flight decks. Initially, critical geometric conformality disruptions can be classified with respect to (at least) the following seven issues:

1) Displacement of the nominal display viewpoint from the nominal eyepoint from which the display is to be viewed

2) Displacement of the pilot's head and eyes from the nominal eyepoint
3) Inappropriate binocular disparity due to lack of stereo imagery or to use of hyperstereo

4) Displacement of display surface from its appropriate location

5) Distortions of depth information due to inappropriate convergence and accommodation cues

6) Display minification

7) Degree and/or type of dissimilarity between display and the view through optical windows

\section{Viewpoint Displacement}

This issue arises when the scene is drawn or generated from a location different from the pilot's eyepoint. As mentioned earlier, this is an inevitable result when a sensor (e.g. a camera) is used to generate viewpoint specific imagery. In that case the distance of the camera (the nominal display viewpoint) from the pilot's head (the nominal eyepoint) introduces a conformality breakage. In the absence of other windows on the flight deck, the major concern here is the possible visual-vestibular conflicts that will arise if the sensor undergoes motions that are difference in magnitude or type from the motion the pilot senses vestibularly. One place where this is a serious concern is during any maneuver where the

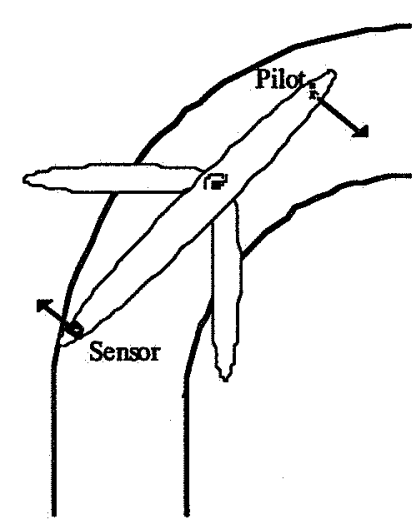

Figure 2. Lateral velocity components of pilot and tail sensor motion during turns. 
aircraft undergoes a change in orientation, and where the pilot and the sensor are at different distances from the center of rotation. In such a case the translational velocities and accelerations may be very different between the two. An extreme example, shown in Figure 2, is where the camera is significantly to the rear of the pivot point of the vehicle, while the pilot is significantly in front of the pivot point. Under test circumstances the pilot and the camera undergo opposite signed lateral accelerations. Another example occurs when there is differential sensor and pilot movement due to elastic aircraft flexing.

\section{Pilot Eyepoint Displacement}

This issue arises when the pilot's head position is not coincident with the display's design eyebox. As noted earlier, when a pilot changes his or her head position within the flight deck in order to get clear views of potentially approaching traffic, both inter-ocular parallax at window edges, as well as a change in what is seen, occurs. Even when there is no significant head motion, the pilot's head and copilot's head are positioned so as to sample substantially different areas of the FOR. For a display that is not sensitive to head position, and/or in situations where the two pilots do not have displays sensitive to their own head position, it may not be possible to get the appropriate view. Figure 1 shows how the ability to see traffic approaching an intersection can be affected when both pilots are forced to view a display that is conformal for a single eyebox centered on one of the pilots, or centered between the two pilots. This figure shows that a display centered on the nominal Captain's position would leave the approaching ground traffic out of sight to the left. However, for virtual windows that are headslaved, the Captain could bring the displayed traffic into his view by moving his head forward, or to the right. In addition to the decreased FOR for the crew, not slaving the eyebox to eyepoint will also cause distortions in the flow patterns within the display. For example, if a crew member's head is left of the correct eyebox location during straightahead motion, the center of optical expansion will no longer be located (correctly) directly in front, but instead it will lie off to a side (see Figure 1). Other optical anomalies are bound to be present also, including probable significant impact to the compellingness of the display. However, the impact on vehicle control and traffic/object avoidance remains to be assessed.

For eyepoint conformality, two different displays are also needed to accommodate the range of different eyepoints required by a pilot and copilot, either of whom may be moving his or her head. Two displays would certainly be needed if an adverse impact on control was found for cross cockpit viewing of a display correct for the other pilot's eyebox (or an eyepoint between the two pilots). In addition, two displays would be absolutely necessary if the eyebox was headslaved, since viewing a display that transformed due to the head movements of another pilot would be extremely disorienting. The critical problem in implementing dual displays is making them viewable only by the appropriate crew member. Several options could be available. First, the cabin could be designed such that the pilot and copilots displays are physically screened from the other member's view by some type of barrier: However, due to the limited space in the cockpit, this option places significant limits on the size of the display each of them could see (and therefore on display FOV). Another would be to provide each crew member with an HMD. This solves the viewability problem, but it is not clear if the needed display resolutions are available in HMDs (or if an HMD would interfere with necessary information exchanges between the crew members). Finally, there are technologies which may allow two eyepoint-specific displays to be presented on the same display surface. These approaches take advantage of the technologies used to provide stereo vision, and give each of the two pilots one of the two eyepoints. These technologies include: LCD shutter glasses (i.e., the view for each pilot is temporally interlaced); lenticular lensed displays (i.e., the view for each pilot is spatially interlaced); and glasses with polarized filters (with the light for the two pilots' views filtered orthogonally). While these approaches also solve the viewability problem, they impose the burdens of decreased resolution, and increased image generation load/faster update rates. 
Finally, information format is another consideration when trying to incorporate headmovements in a virtual window. While transformations due to head movement can (in principle) be captured easily by systems using coordinate-based information formats (e.g. computer-generated imagery), systems based upon viewpoint-based formats would need to translate a camera in 3 axes to fully mimic head movements. On the other hand, it is possible that some of the viewpoint warping techniques (or camera zoom and pan) may be sufficient for a compelling and effective display.

\section{Stereo Vision Anomalies}

This issue arises whenever a display does not provide for stereo viewing, or provides hyperstereo. The lack of stereo vision generates two potentially problematic effects. First, a binocular view through a window yields significant inter-ocular parallax at the window edges and an increased FOR; a non-stereo display provides neither. The lack of the increased FOR impacts the functional utility of the display in the same manner as described in the issue above, while the lack of parallax at the window edges has its impact on the compellingness of the display. The use of hyperstereo (using two viewpoints or camera locations separated by a much greater distance than that between the two eyes) has its own benefits and problems. On the positive side, the appreciation of relative depth is greatly enhanced, as is the compellingness of the display. On the downside is the fact that people are accustomed to their natural eye separation, and thus hyperstereo effectively miniaturizes the world (i.e. the increased stereo disparity is consistent with viewing a much smaller world). This can lead to misjudgments of size and depth, and could potentially lead to vestibular-visual side-effects when the visual changes appear to specify a small motion, while the vestibular system detects a much larger motion.

Second, for objects that are within range of stereo vision, a stereo image provides depth or distance information. The importance of this property is a direct function of the distance between the window and the objects. The potentially most important situation where stereo vision could be valuable is during the approach to a gate. Here stereo vision could provide important distance information if the virtual window occupies a (virtual) position close to the nose of the craft. Again, the lack of stereo could also adversely impact the compellingness of the display.

\section{Display Displacement}

This issue arises when a display is not correctly located on the flight deck. A forward-looking display should be in front of a pilot; the horizon line should be at eye level. Otherwise the display is misplaced. During surface operations the misplacement of the horizon line, in combination with vestibular cues given by the vector of gravity, generate a cue conflict that may lead to physiological side effects. This possibility should be examined particularly for cases where there are significant longitudinal accelerations/decelerations, because these are known to create pitch attitude illusions. In such instances a pilot may have trouble determining when the illusion of pitch change is due to a misplaced horizon, and when it is due to acceleration.

\section{Inappropriate Convergence/Accommodation Cues}

This issue refers to the fact that the degree of visual convergence and the amount of accommodation, when focusing on an object through a window, is informative about the distance of that object. When focusing on a display surface, these cues specify that the object is very close and two dimensional. Often, an attempt will be made to eliminate the perception of the display surface by using collimating optics which generate accommodation and convergence cues that indicate that everything is at some fixed distance (the exact distance depends upon the design of the collimating lens). While collimation may be added to generate the perception of a deep scene, compelling collimated displays may lead pilots to believe and act upon the resulting (and faulty) information about depth being provided by the accommodation/ convergence depth cues. This may be a particular problem during close encounter situations such as docking at gates. 

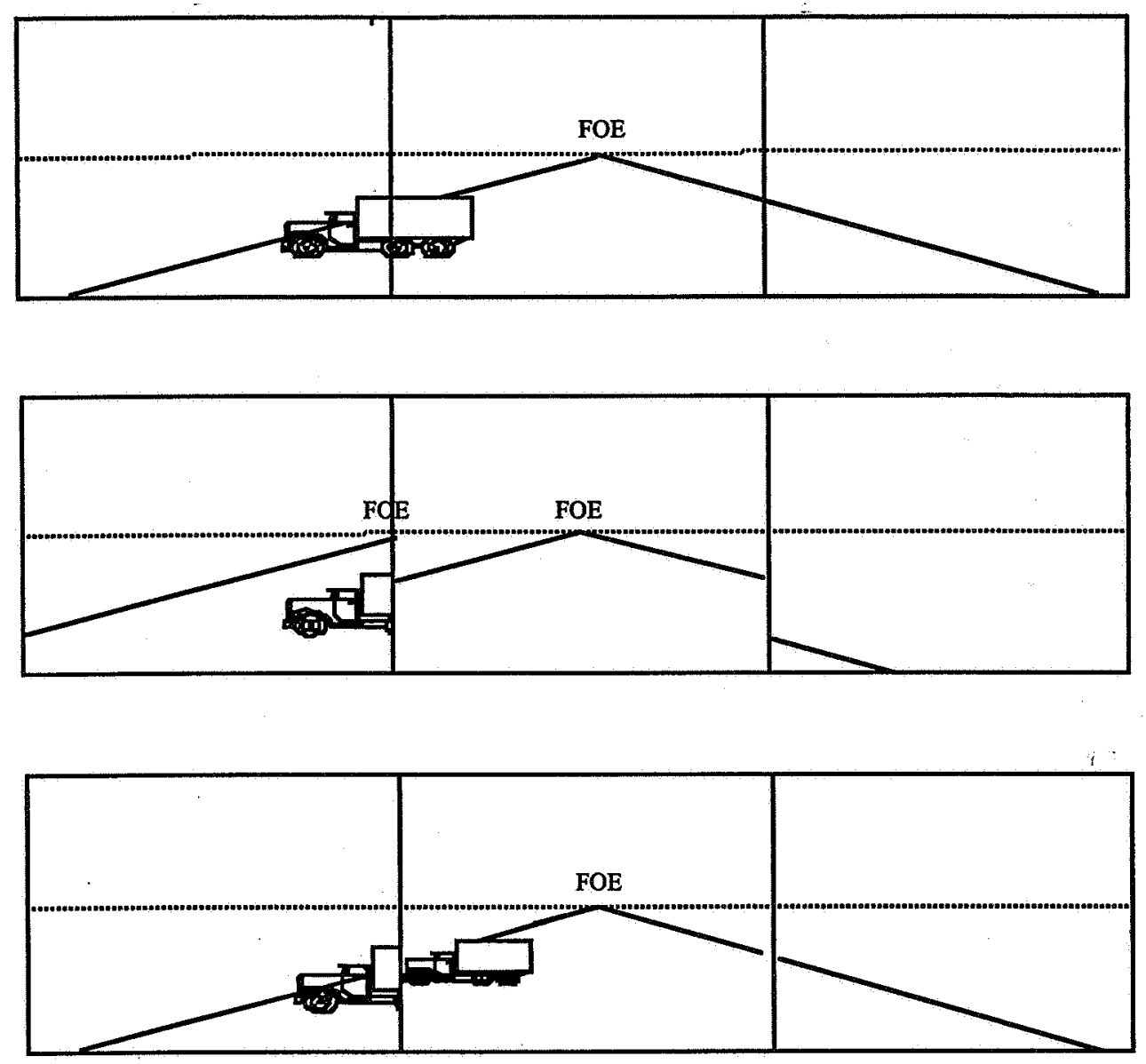

Figure 3. Views of $13 \mathrm{ft} . \times 40 \mathrm{ft}$. truck located $25 \mathrm{ft}$. in front of pilot on taxiway. The two side views are through optical windows and the middle view is from a non-headslaved virtual window, with the sensor viewpoint located $2 \mathrm{ft}$. from, and directly in front of the virtual window. The top panel shows the view when the observer is in the center position (no eyepoint displacement). The middle panel is the view from the captains position (eyepoint displaced $1 \mathrm{ft}$. to the left). The bottom panel is the view from the center position, but with a $30 \%$ minification of the center virtual window.

\section{Display Minification}

This issue refers to the fact the display may be minified in order to fit more virtual space into some restricted display area (see Figure 3, bottom panel). When a display is minified apparent distance changes. Just like many side view mirrors on automobiles, the display should be labeled with "OBJECTS IN YOUR DISPLAY ARE CLOSER THAN THEY APPEAR". But this is not the only effect, with concomitant distortions in apparent velocity and even in the apparent slant of surfaces (or in glideslope).

\section{Virtual/Optical Window Conflict}

This issue is, in many ways, the most complex and dangerous one of all since all of the above issues feed into it. Issue 7 refers to the fact that the physiological side effects of disorientation can arise when both a synthetic display and a real window are present on a flight deck, and no consistent visual interpretation is available. For example:

1) Viewpoint Displacement: Even if displacement or a camera is not sufficient 
to generate a significant visual-vestibular decoupling, the displacements may generate strong visual discrepancies between the window and the display during ground operations. For example, vertical displacements of the camera will be generate discrepancies in alignment of the imagery in the display and the real windows that are a function of the ratio of camera height to the height of the pilot above the ground. These discrepancies include shifts in apparent position (Figure 3 , middle panel) and in apparent speed of motion.

2) Pilot Eyepoint Displacement: Vertical motions of the head will cause the scene in the window to transform, but unless head tracking is incorporated, the transformations will not be reflected in the display. Thus there is visual-vestibular coupling in one location and not in the other, which in turn may impact both compellingness and (dis)orientation.

3) Stereo Vision Anomalies: Lack of binocular disparity in the display will produce a very different impression than looking through a true window. For surface operations where objects are truly close and within the range of stereo vision, this may interfere with the compellingness of the display as a virtual window.

4) Display Displacement: Vertical displacements (which are the most likely) will strongly decouple the windows from the display. As with the above, this may interfere with the compellingness of the display, as well as lead to disorientation and difficulties in determining the spatial correspondence between the objects as they pass between the views of the display and the optical windows.

5) Inappropriate Convergence/Accommodation Cues: The side window will have full convergence accommodation cues. How this will affect the pilot will probably depend on how peripheral vision is affected by these cues.

6) Display Minification: Minification will naturally result in angular displacements, and angular size differences, between the similar sized and located objects in the display and in the optical windows. All of the potential problems noted for displacement of display surface from appropriate location will apply. In addition disorientation that may also result from the contrast between the distance/speed information distortions caused by minification and the natural view in the windows.

Finally, perhaps the most dangerous aspect of the optical window issue is that we do not know how well a pilot can focus on the central display and ignore optical windows during an emergency situation where quick reactions are involved. The bottom two panels of Figure 3 show how side optical windows and a fixed perspective center display could generate clashing optical geometries, If the differences between the side optical and a display introduce some element of visual confusion, then this could result in longer response times while the pilot resolves the conflict.

\section{Dynamic Conformality}

Dynamic conformality is actually a variety of geometric conformality since it also is distorted only when the locations of the imaged objects within the virtual space do not overlap the optical locations of the real objects when directly viewed by the observer. However, dynamic conformality deserves to be treated separately as a result of its special character, i.e. it can be achieved only when the events in the physical space, and their depiction in the virtual space, occur simultaneously. The main disruptions in dynamic conformity are due to lags between when a scene should be updated and when it actually is updated. These lags, in turn, are due to update rate (frames per second being displayed) and to overall system lag (the time it takes to determine what should be displayed, and then to actually display it). The 
update rate determines part of the overall system lag, but does not fully determine it. For example, a system may depend upon a camera that samples images 50 times a second, every $20 \mathrm{~ms}$. In addition, however, it may take another $100 \mathrm{msec}$ to process and display this image. This will generate a full $120 \mathrm{~ms}$ lag.

While there are several factors determining how fast a virtual window must be updated, it must be fast enough that the displayed motion appears smooth. This is a function of update rate, the angular visual velocity being generated, and whether the image is discrete or time-sampled (i.e. motion-blurred). A displayed motion is most smooth when the angular distance between successive updates (angular velocity/update rate) is sufficiently small that smooth apparent motion is obtained. The required update rate will not need to be as high if the virtual window is displayed on a fixed panel, and not within an HMD. This is because the optical pattern within the virtual window is invariant over changes in the pilot's gaze direction, but the location of the virtual window in retinal space does change. For a panelmounted display the change in virtual window location in retinal space occurs automatically when head orientation changes, whereas it must be computed and updated when it is being drawn on an HMD. This can be a very significant factor since head rotation rates can generate angular motions in excess of 100 degrees/sec, much higher than the angular motions that result from simple translational head shifts.

Another significant factor in determining required update rate is the likely angular visual velocities that must be displayed as a function of vehicular motion. These angular velocities are affected by three factors. The first factor is the angular rate of craft rotation during turns, which introduces angular optical velocities. The other two factors are functions of vehicle translation, and are 1) vehicle path speed divided by the range to the viewed object; and 2) the relative angle between the line of sight to the object and the velocity vector of the aircraft. Since surface movements do not often generate high rates of vehicle rotation, this factor can probably be safely ignored when determining required update rates. On the other hand, landing speeds on the order of 150 knots are expected for the high-speed transport aircraft of the future. Range to the viewed object is somewhat more difficult to assess since it will depend on the location of display viewpoint (e.g. camera location if a camera is generating the display, or pilot location if computer-generated imagery is being used to simulate the window that a pilot could be expected to see-through the virtual window), and the FOV. However, if we assume a fully conformal standard window that has a lookdown angle of 20 degrees, with the display viewpoint located $25 \mathrm{ft}$ above the runway/taxiway, this will generate angular motions of $67 \mathrm{deg} / \mathrm{sec}$ at the bottom of the virtual window. Although a $60 \mathrm{~Hz}$ update rate may provide an adequate display for this situation, locating a display viewpoint (e.g. camera or CGI viewport) below this will cause the angular motions to rise proportionately (e.g. the angular motions would be $134 \mathrm{deg} / \mathrm{sec}$ if the display viewpoint was at 12.5 $\mathrm{ft})$. And using a vertical FOV/viewpoint orientation with a lookdown angle of 30 degrees at $25 \mathrm{ft}$ would cause the angular rate to rise to $1.44 \mathrm{deg} / \mathrm{sec}$. Thus it is clear that the required update rate is strongly influenced by the placement and orientation of the display viewpoint.

Dragging, the perception that a display is not keeping up with head motion, is due to system lags which delay the update of the display. When the display lag is coupled with independent (nondisplay), and non-lagged, information that the head has changed location. Therefore, apparent dragging could be expected to be most salient when the non-lagged information for head movement is salient, and/or the system lag is high. For a virtual window displayed in an HMD, only the vestibular system provides this independent information that the head has moved; while for a panel-mounted virtual window the change in the visible flight deck layout due to change in head location also provides this independent information. Therefore apparent dragging may be a more significant problem for panel-mounted virtual windows than for those displayed within an immersive HMD. Similarly, when synthetic scenelinked imagery is overlaid on a HUD, distortions 
due to lags will be very obvious. In addition, it should be noted that the total system lags or transport delays often considered acceptable for flight simulation (often put at around 100-200 $\mathrm{msec}$ ) should not be extrapolated to form the bases for acceptable visual-visual or visualvestibular lags, since inter-sensory/intra-sensory discrepancies should be much more noticeable.

Finally, it may be possible to use predictive algorithms to compensate for some of the lags present in these systems. Such algorithms, which extrapolate over the expected lag period, are used in simulators to compensate for system lags. When using CGI imagery based upon a known database it is possible to use such predictive algorithms to remove lags in displays by using your present rates of change to estimate the expected future position that compensates for your lag. However, when the scene within the virtual window is based upon an image-based sensor, such as an optical or infrared camera, there is no independent database that can be used to describe what the scene will look like after you have moved by the expected amount and in the expected direction. Therefore, these algorithms can only be used if a suitable image warping technology is available.

\section{Conclusion}

For any standard application upon a flight deck, making a geometrically and dynamically correct virtual window will likely require a range of technologies (head-tracking, image-warping, displays separately viewable by the crew members, etc.). This is because a flight deck contains a crew, not just a single pilot. In addition, both crew members move their heads, especially during taxi operations, and any perspective display emulates the view from a true window only from a single eye position. Therefore, allowing dynamic head movements requires feeding this position back into the display generation system in a timely manner. This requires a system that has a sufficiently low lag, sufficiently high update rate, and a sufficiently high degree of accuracy. It is most likely that any system that is implemented in the foreseeable future will remain constrained by limitations in technology, and by other impinging flight deck design criteria (such constraints on available space for displays or the desire for optical windows in the aircraft). Preparation for implementing these designs requires, therefore, a systematic evaluation of the impacts of display conformality compromises.

\section{References}

1. G. E. Cooper, and R. P. Harper, Jr., "The Use of Pilot Rating in the Evaluation of Aircraft Handling Qualities", NASA TN-D-5153, 1969.

2. E. Moralez, V. K. Merrick, and J. A. Schroeder, "Simulation evaluation of an advanced control concept for a V/STOL aircraft", Journal of Guidance, Control, and Dynamics, 12, 334-341, 1989.

3. R. S. Bray, "A head-up display format for application to transport aircraft approach and landing", NASA TM 81199, 1980.

4. I. D. Haskell, and C. D. Wickens, "Two and three-dimensional displays for aviation: A theoretical and empirical comparison", The International Journal of Aviation Psychology, $\underline{3}, 87-110,1993$.

5. S. V. Bemis, Leeds J. L., and E. A Winer, "Operator performance as a function of type of display: Conventional vs. perspective", Human Factors, 30, 15-24, 1988.

6. C. D. Wickens, I. D. Haskell, and K. Harte, "Ergonomic design for perspective flight path displays", IEEE Control Systems Magazine, 9 , 3-8, 1989.

7. A. J. Grunwald, J. B. Roberston, and J. J. Hatfield, "Experimental evaluation of a perspective tunnel display for threedimensional helicopter approaches", Journal of Guidance and Control, 4, 623-631, 1981.

8. W. W. Johnson, and C. A. Awe, "The selective use of functional optical variables in the control of forward speed", NASA TM $108849,1994$.

9. D. H. Owen, L. Wolpert, and R. Warren, R. "Effects of optical flow acceleration, edge acceleration, and viewing time on the perception of egospeed acceleration", in D.H. Owen (Ed.), Optical flow and texture variables useful in detecting decelerating and accelerating self-motion, AFHRL TP-84-4, 
AD-A148 718, Williams, AFB, AZ, Operations Training Division, Air Force Human Resources Laboratory, 1984.

10. R. A. Peters, "Dynamics of the Vestibular System and Their Relation to Motion Perception, Spatial Disorientation, and Illusions", NASA CR-1309, 1969.

11. D. H. Owen, "Perception and control of rotorcraft flight", in W.W. Johnson and M. K. Kaiser (Eds.), Visually Guided Control of Movement, NASA Conference Publication 3118, NASA Ames Research Center, Moffett Field, California, pp. 87-97,1991.

12. D. H. Owen, "Alternative modes of control and visual information for rotorcraft flight", Interim Technical Report for NASA Grant No. NAGW-2170, Christchurch, New Zealand: University of Canterbury, Department of Psychology, Simulation Laboratory, 1993.

13. D. H. Owen, "Compatibility of information and mode of control: The case for natural control systems", in C. L. Blanken, J. V. Lebacqz, R. H. Stroub, and M. S. Whalley (Eds.), Proceedings of piloting vertical flight aircraft: A conference on flying qualities and human factors, NASA Conference Publication 3220, San Francisco, California: American Helicopter Society/NASA, pp. 3.1 - 3.6, 1993.

14. W. W. Johnson, and A. D. Andre, "Visual cueing aids to rotorcraft landings", in C. $L$. Blanken, J. V. Lebacqz, R. H. Stroub, and M. S. Whalley (Eds.), Proceedings of piloting vertical flight aircraft: A conference on flying qualities and human factors, NASA Conference Publication 3220, San Francisco, California: American Helicopter Society/NASA, pp. 4.1 - 4.20, 1993.
15. D. H. Owen, and W. W. Johnson, "An information based approach to simulation research", in R. A. Feik, (Ed.), Proceedings of the Future Directions in Simulation Workshop. Melbourne, Australia: Defence Science and Technology Organisation, Aeronautical Research Laboratory, Aircraft Systems Division, 1992.

16. W. W. Johnson and J. A. Schroeder, "Visual and Motion Cueing in Altitude and Yaw Control", presented at the 37th Annual Meeting of the Human Factors Society, 1994.

17. M. Johnson, and C. Rogers, "Photo-realistic scene presentation: "virtual video camera" ", Proceedings of SPIE Conference on Sensing. Imaging and Vision for Control and Guidance of Aerospace Vehicles, p 294-302, 1994.

18. K. W. Arthur, K. S. Booth, and C. Ware, "Evaluating 3D task performance for fish tank virtual worlds", ACM Transactions_on Information Systems, 11, 239-265, 1993.

19. R. S. McCann, and D. C. Foyle, "Superimposed symbology: Attentional problems and design solutions", $\underline{\text { SAE }}$ Technical Paper Series 94211, Warrendale, PA: SAE International, 1994. 


\begin{tabular}{|c|c|c|c|c|}
\hline \multicolumn{2}{|c|}{ Report Documentation Page } & \multicolumn{3}{|c|}{$\begin{array}{c}\text { Form Approved } \\
\text { OMB No. 0704-0188 }\end{array}$} \\
\hline \multicolumn{5}{|c|}{ 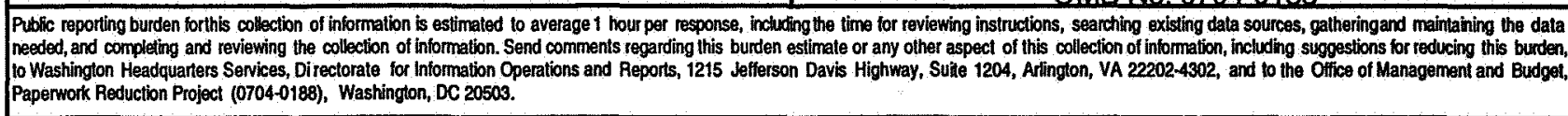 } \\
\hline 1. AGENCY USE ONLY (Leave blank) & \multicolumn{2}{|c|}{$\begin{array}{l}\text { 2. REPORT DATE } \\
\text { December } 2003\end{array}$} & \multicolumn{2}{|c|}{$\begin{array}{l}\text { 3. REPORT TYPE AND DATES COVERED } \\
\text { Technical Memorandum }\end{array}$} \\
\hline \multicolumn{3}{|c|}{$\begin{array}{l}\text { 4. TITLE AND SUBTITLE } \\
\text { Perspective Imagery in Synthetic Scenes used to Control and Guide } \\
\text { Aircraft during Landing and Taxi: Some Issues and Concerns }\end{array}$} & \multicolumn{2}{|c|}{ 5. FUNDING NUMBERS } \\
\hline \multicolumn{3}{|c|}{$\begin{array}{l}\text { 6. AUTHOR(S) } \\
\text { Walter W. Johnson and Mary K. Kaiser }\end{array}$} & & \\
\hline \multicolumn{3}{|c|}{$\begin{array}{l}\text { 7. PERFORMING ORGANIZATION NAME(S) AND ADDRESS(ES) } \\
\text { NASA Ames Research Center } \\
\text { Moffett Field, California } 94035-1000\end{array}$} & \multicolumn{2}{|c|}{$\begin{array}{l}\text { 8. PERFORMING ORGANIATION } \\
\text { REPORT NUMBER } \\
\text { IH-047 }\end{array}$} \\
\hline \multicolumn{3}{|c|}{$\begin{array}{l}\text { 9. SPONSORING/MONITORING AGENCY NAME(S) AND ADDRESS(ES) } \\
\text { National Aeronautics and Space Administration }\end{array}$} & \multicolumn{2}{|c|}{$\begin{array}{l}\text { 10. SPONSORINGMONITORING } \\
\text { AGENCY REPORT NUMBER } \\
\text { NASA/TM-2003-212808 }\end{array}$} \\
\hline \multicolumn{5}{|c|}{$\begin{array}{l}\text { 11. SUPPLEMENTARY NOTES } \\
\text { Point of Contact: Walter W. Johnson, M/S 262-2, Ames Research Center, Moffett Field, CA } 94035 \\
\qquad(650) 604-3667\end{array}$} \\
\hline \multicolumn{3}{|c|}{$\begin{array}{l}\text { 12A. DISTRIBUTION/AVAILABILITY STATEMENT } \\
\text { Subject Category: 54-03 } \\
\text { Availability: NASA CASI (301) } 621-0390\end{array}$} & \multicolumn{2}{|c|}{ 12B. DISTRIBUTION CODE } \\
\hline \multicolumn{5}{|c|}{$\begin{array}{l}\text { 13. ABSTRACT (Maximum } 200 \text { words) } \\
\text { Perspective synthetic displays that supplement, or supplant, the optical windows traditionally used for } \\
\text { guidance and control of aircraft are accompanied by potentially significant human factors problems } \\
\text { related to the optical geometric conformality of the display. Such geometric conformality is broken } \\
\text { when optical features are not in the location they would be if directly viewed through a window. This } \\
\text { often occurs when the scene is relayed or generated from a location different from the pilot's } \\
\text { eyepoint. However, assuming no large visual/vestibular effects, a pilot can often learn to use such a } \\
\text { display very effectively. Important problems may arise, however, when display accuracy or } \\
\text { consistency is compromised, and this can usually be related to geometrical discrepancies between how } \\
\text { the synthetic visual scene behaves and how the visual scene through a window behaves. In addition to } \\
\text { these issues, this paper examines the potentially critical problem of the disorientation that can arise } \\
\text { when both a synthetic display and a real window are present in a flight deck, and no consistent visual } \\
\text { interpretation is available. }\end{array}$} \\
\hline \multirow{2}{*}{\multicolumn{4}{|c|}{$\begin{array}{l}\text { 14. SUBJECT TERMS } \\
\text { Synthetic vision, Cockpit displays, Perspective displays, Display } \\
\text { conformality, Human factors }\end{array}$}} & $\begin{array}{c}\text { 15. NUMBER OF PAGES } \\
13\end{array}$ \\
\hline & & & & 16. PRICE CODE \\
\hline $\begin{array}{l}\text { 17. SECURITY CLASSIFICATION } \\
\text { OF REPORT }\end{array}$ & $\begin{array}{l}\text { 18. SECURITY CLASSIFICATION } \\
\text { OF THIS PAGE }\end{array}$ & $\begin{array}{l}\text { 19. SECURITY CL } \\
\text { OF ABSTRA }\end{array}$ & ATION & 20. LIMITATION OF ABSTRACT \\
\hline Unclassified & Unclassified & Unclassified & & Unlimited \\
\hline NSN 7540-0 & & & & $\begin{array}{l}\text { Form } 298 \text { (Rev. } 2 \\
\text { oy ANSI Std. Z-39-18 }\end{array}$ \\
\hline
\end{tabular}

